\title{
LAW AND MEDICAL ETHICS
}

\section{Consent, sectionalisation and the concept of a medical procedure}

A R Maclean

Correspondence to:

Mr A R Maclean, The

School of Law, The Stair

Building, The University of

Glasgow, Glasgow

G12 8QQ;

a.maclean@law.gla.ac.uk

Consent transforms an otherwise illegitimate act into a legitimate one. To be valid, however, it must be adequately informed. The legal requirement is vague and provides little assistance in predicting when it will be satisfied. This is particularly so when a patient consents to a procedure and the physician sub-

Revised version received 8 February 2002

Accepted for publication

12 March 2002 sequently varies one of the components of that procedure. Using three legal judgments and one General Medical Council (GMC) decision as a springboard, I have explored the concept of a medical procedure within the context of consent and developed a theoretical model to elucidate a more predictable and consistent informational requirement.

B fore performing a medical procedure, a doctor must obtain her patient's consent. This obtains legally, professionally, and ethically. The "magic" of the patient's consent is that it transforms the status of an act from illegitimate to legitimate. ${ }^{1}$ Both morally and legally, the patient's right to give or withhold consent flows from his right to (respect for) autonomy. ${ }^{2}$ Although the meaning of autonomy is debated it is not contentious to suggest that, at a minimum, autonomy requires the capacity to make a decision. Similarly, it is perhaps fair to suggest that knowledge of the decision is a prerequisite for exercising decision making capacity.

In the context of a medical procedure, knowledge of the decision demands that the patient have a sufficient understanding of what that procedure entails to be able to determine how it would likely affect him and, on that basis, whether or not to give his consent. To gain a sufficient understanding requires information and that information lies with the doctor. At present the law simply requires that the patient is informed "in broad terms" about the nature of a procedure. ${ }^{3}$ Without determining what is-or should bemeant by the "nature" of a procedure, however, it is difficult to predict when sufficient information is imparted. This engenders the risk of inconsistency and uncertainty. In particular, a difficulty arises in determining whether altering a component of a medical procedure invalidates a prior consent. Based on three legal judgments and one GMC decision, I will develop a theoretical model of a medical procedure with the aim of constraining inconsistency and enhancing the communication process of consent.

\section{THE CASES}

Davis v Barking, Havering and Brentwood Health Authority ${ }^{4}$

The claimant consented to a general anaesthetic for a minor gynaecological operation. No mention was made of the caudal anaesthetic subsequently performed after she had been anaesthetised. ${ }^{5}$ Following the procedure, she was left with a "minor but significant" bladder disorder and sensory abnormality in her left leg. She sued in trespass (battery) claiming that she had not consented to the caudal anaesthetic.

In finding the defendants not liable, McCullough J held that consent for the caudal was subsumed by consent for the general anaesthetic. He suggested that to accept the plaintiff's claim would result in a sectional approach to consent. McCullough J's distaste for this approach was evidenced when he stated: "A sectionalised approach of this kind would encourage-indeed necessitate-what has been called the 'deplorable' prospect of actions being brought in trespass rather than in negligence". ${ }^{6}$ Thus, he argued: "Whether a particular aspect of what is proposed is a matter of detail or is in reality in a matter sufficiently separate to call for separate mention is a question of fact and degree.

"In my judgment, there is no realistic distinction between omitting to tell a patient that while she is under a general anaesthetic a tube will be put in her trachea ... and omitting to tell her that while she is under a general anaesthetic a needle will be put into her caudal region to provide postoperative analgesia."

\section{The General Medical Council case ${ }^{7}$}

During a chair dental anaesthetic, a consultant anaesthetist inserted a rectal suppository to provide postoperative analgesia. Although the patient, a young woman, had consented to the anaesthetic she had not been asked for her consent to the suppository, as his usual practice was to inform the patient after the procedure was finished. A complaint was lodged with the GMC and the anaesthetist was charged with serious professional misconduct for "assault" (not in the legal sense) and failure to obtain an informed consent.

The anaesthetist defended his action by arguing that the suppository, as postoperative pain relief, was part of the anaesthetic and was thus subsumed by her consent to the general anaesthetic. The GMC rejected this and drew a particular distinction between anaesthesia in hospital and anaesthesia in a dental surgery. They further rejected McCullogh J's warning about the dangers of sectionalising consent. The thrust of the GMC's argument was that, because they retain their own clothes and underwear during treatment, patients would not expect interference with the lower part of their body. Thus, the anaesthetist was found guilty of serious professional misconduct.

\section{The US cases}

Both cases involved a claim that the claimants had not consented to the use of forceps during a vaginal delivery. In Rizzo $v$ Schiller, the defendant used forceps once it became clear that the claimant was unable to push out her baby without assistance. Unfortunately this resulted in brain injury. Although, the defendant informed the claimant that he was going to use forceps immediately before applying them to the baby's head, there was no opportunity for discussion and her 


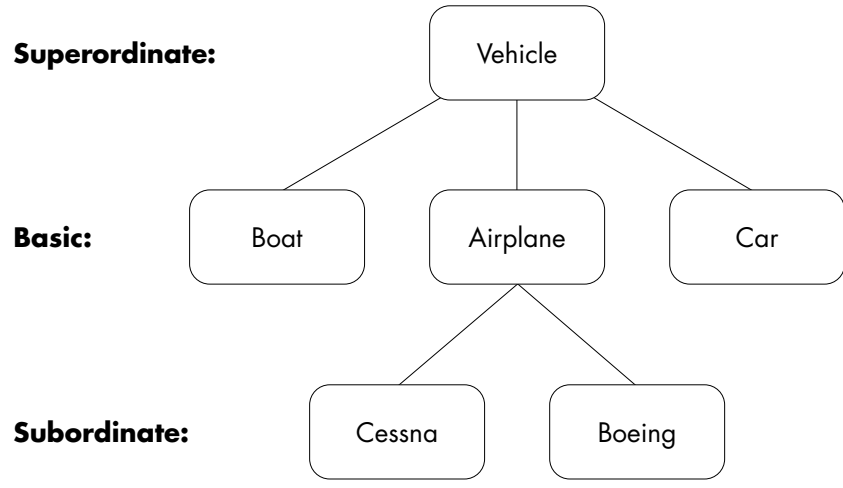

consent was not sought at this point. The claimant had, however, signed a general consent form authorising the performance of "diagnostic or therapeutic medical and surgical procedures". ${ }^{8}$ Although there was no specific mention that the use of forceps may be necessary, the defendant argued that the claimant "was allowed to participate in the decision to use forceps". " The Supreme Court of Virginia disagreed and argued that a discussion of the specific procedure was required.' It held that there was sufficient evidence to establish a prima facie case of negligence for failing to obtain an informed consent. Since there was no complaint in relation to the consent for manual vaginal delivery, it is implicit that the court did not believe consent for forceps to be subsumed within that consent.

In contrast, in Sinclair by Sinclair v Block, the Supreme Court of Pennsylvania held that the physician was not liable. ${ }^{10}$ Because descent had "arrested" and the baby's heart had slowed, the defendant attempted a forceps delivery. This attempt failed and the baby was delivered by a caesarean section. Unfortunately, the attempted forceps delivery fractured the baby's skull and left him with epilepsy. As in Rizzo, the claimant signed a general consent form that referred to "delivery care . . and/or caesarean section". ${ }^{11}$ In holding that the doctrine of informed consent did not apply, Nix C J stated: "Under the circumstances of this case ... we find that the physician's attempt to use forceps is part of one event: the natural delivery process. Thus, the physician's use of forceps to facilitate natural delivery is not a distinct surgical or operative procedure and, as a result, does not require additional consent". ${ }^{12}$

\section{DISCUSSION}

It is clear from these cases that completely disparate results may be arrived at despite working with the same basic principle, namely, respect for autonomy. I will argue that the approach adopted by the GMC and by the court in Rizzo is preferable to the one used by the court in Davis and Sinclair. To do that, I will discuss the concept of a medical procedure and develop a theoretical model to support that claim.

The main difficulty with Davis and Sinclair is that the concept of a medical procedure was oversimplified. Whilst the concept of a medical procedure may be straightforward in an everyday sense-a blood test is a single procedure, as is an appendicectomy - it becomes more complicated when looked at more closely. My starting point for this inquiry is to consider concepts in general, how we organise our concepts, and the utility of that organisation.

\section{Concepts and concept hierarchies}

There are many theories of concepts, such as prototype or exemplar theories, ${ }^{13}$ but this is not the place to discuss their pros and cons. For the purpose of this paper I will adopt the "theory based" view of concepts, which suggests concepts are categorised and individuated on the basis of their attributes,
Figure 1 A simple hierarchy.

\section{Distinctiveness}

and an underlying theory that explains those attributes. ${ }^{14}$ The concepts we possess tend to be organised in hierarchies (see figure 1). When communicating, the particular concept we choose depends on its utility. ${ }^{15}$ This depends on the context of its use, but involves a trade-off between distinctiveness and informativeness. ${ }^{16}$ Thus, high level concepts carry little information but are easy to distinguish, while low level concepts are more informative but harder to individuate.

At this point, it may be useful to provide an example. Consider a hierarchical classification of "living things". It is easier to distinguish an animal from a plant than it is to distinguish a dog from a rabbit and to understand what an animal is requires less information than to understand the concepts of rabbit and dog. Similarly, it is easier to distinguish a dog from a rabbit than a labrador from a golden retriever and understanding the concept of a labrador requires more information than is needed to grasp the concept of a dog. The obverse is equally true. Just as more information is required to understand the concept of a labrador as opposed to a dog, so using the term "dog" as a referent tells the hearer less about the object referred to than if the "dog" is described as a labrador or a golden retriever. ${ }^{17}$

The level of the hierarchy that a person uses will depend on their knowledge of the concepts within that hierarchy and the information they wish to communicate. Non-experts tend to choose concepts that achieve a reasonable balance between both information and distinctiveness, and this level in the hierarchy is termed the "basic level". ${ }^{18}$ Experts operate at a "subordinate level" to this. This is relevant because the amount of information that must be communicated to allow the recipient to grasp a lower level concept is greater than that required to grasp a high level concept. Thus, returning to my earlier example, to grasp the concept of a labrador the hearer must understand the concept of dog, the concept of breeds of dogs, and the attributes possessed by a labrador that distinguish it from other breeds of dog. In the context of consent, this is important because the higher up the hierarchy we operate (dog being higher than labrador), the easier it is to satisfy the informational requirements of the concept.

Using an anaesthetic hierarchy as an example (see figure 2), if consent operates at the basic level or higher (superordinate level) then the informational requirements are minimal. If we assume (for the present purpose) that < general anaesthetic $>$ and $<$ local anaesthetic $>$ are basic level concepts then it would be unnecessary to discuss any variation of the components of the anaesthetic. Providing the patient grasped that it was either a < general anaesthetic $>$ or a <local anaesthetic $>$ the physician's duty to inform would be satisfied. This is the approach adopted in Davis and in Sinclair. It is submitted, however, that this is inadequate to satisfy the patient's informational needs. To demonstrate this, it is necessary to consider the concept of a medical procedure in greater depth. 


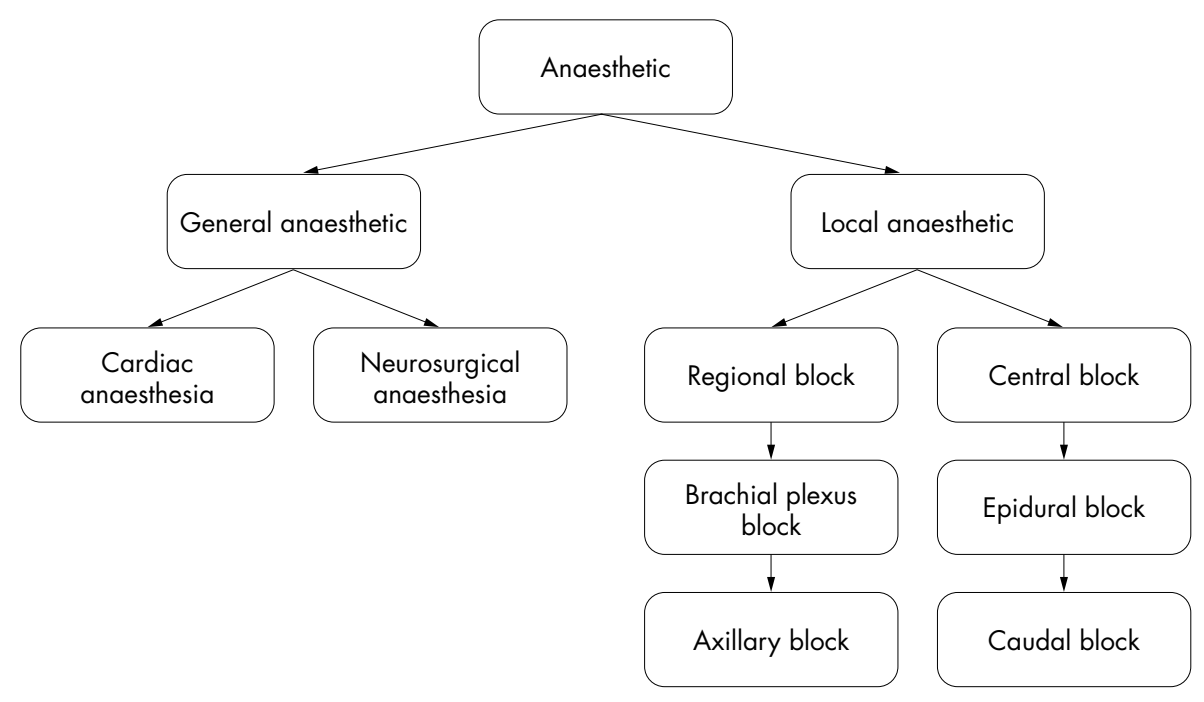

Figure 2 Anaesthetic procedure hierarchy (incomplete).

\section{The concept of a medical procedure} i) Attributes

A medical procedure is artefactual rather than natural. The procedures are developed and adapted, by health care professionals, to provide the most efficient mechanism to achieve the desired benefit. The purpose of the procedure, and the means adopted to effect that purpose, generate the attributes associated with the procedure. Together with an underlying theory that relates means to aim, the values of these attributes distinguish one medical procedure from another. The further down the hierarchy one goes, the more discrete these attribute values become and the more information they entail. The attributes that may be associated with a medical procedure include:

1. Time course - Every procedure must have a beginning and an end although the duration may be extremely variable and will be both operator and patient dependent;

2. Purpose-Each procedure must have a particular purpose, thus, the purpose of taking a blood sample is to obtain sufficient blood for the laboratory to perform the requisite diagnostic test;

3. Aim-Each procedure must aim to provide a benefit. The benefit may be primarily for the patient or for third parties.

3.1. Direct-treatment procedures that aim to cure, control or retard a disease process and those that aim to alleviate particular symptoms;

3.2. Indirect-diagnostic procedures that, by increasing the accuracy of the doctor's diagnosis, indirectly benefit the patient because a more accurate diagnosis allows a more appropriate treatment.

3.3. Altruistic - these procedures primarily benefit others. Thus, live organ transplants benefit the recipient and non-therapeutic research may benefit future patients.

4. Mechanics - The mechanics of a procedure include:

4.1. A number of actions on the patient that are unified by the underlying theory of the procedure;

4.2. One or more anatomical sites;

4.3. A mechanism-for example, repair, removal, ablation, transplantation, excision, implantation, injection, insertion, and inhalation;

5. Effects-These are the characteristic consequences of the procedure which may be:

5.1. Intended-The loss of a patient's spleen is an intended consequence of a splenectomy;
5.2. Unintended-The side effects of a procedure, such as the susceptibility to pneumococcal infections that follows a splenectomy;

6. Risks-The potential consequences that may result when the procedure has not gone according to plan, such as a dural puncture when performing an epidural local anaesthetic.

At this point it is worth remembering that, in all of the cases described earlier, the procedure was varied from that which the patient was led to believe would be performed. Thus, in Davis and the GMC case, the anaesthetist varied the analgesic component of the anaesthetic. In Rizzo and Sinclair, the obstetrician varied the mode of delivery. These variations have a number of things in common. Although they do not, necessarily, alter the aim, purpose, or time course (within reasonable limits) of the procedure, they do affect the mechanics, effects, and the associated risks of the procedure. Whether this changes the nature of the procedure depends on the operating level of the hierarchy. At a higher level, the attributes are abstract enough to absorb the changes. Thus, a procedure remains a general anaesthetic regardless of whether the analgesia is intravenous, caudal, or rectal. At a lower level of the hierarchy, the attributes become so distinct that a change in analgesia alters the procedure sufficiently to create a new procedure, which requires a different consent from that given for the expected procedure.

It is important to note that altering, or adding, a component will not always affect the attributes of the procedure in a manner that is relevant to the patient. The effect of any change will be context dependent. For example, using one particular type of suture or another will usually be of no interest (in the consent context) to a patient. The patient's past experience may, however, change this situation. If the patient has had a previous allergic reaction to a particular type of suture material then the choice of suture material does become relevant. In this case, the effects attribute is affected by the choice of suture.

There is no point, in this context, in being given information simply for information's sake. Consent serves a particular purpose, which is to allow patients the dignity of determining for themselves how their bodies are interfered with. It is also arguable that far from being required, irrelevant information may be damaging-by confusing or misdirecting the patient-thus imposing a duty on the physician to disclose only that which is truly necessary for the decision in question. ${ }^{19}$ It is submitted that the information elements relevant in the consent context are: the aim and purpose of the procedure; the area and extent of any breach of bodily integrity, and the effects and the risks of the procedure. Any variation that alters one of these should be presented to the patient 


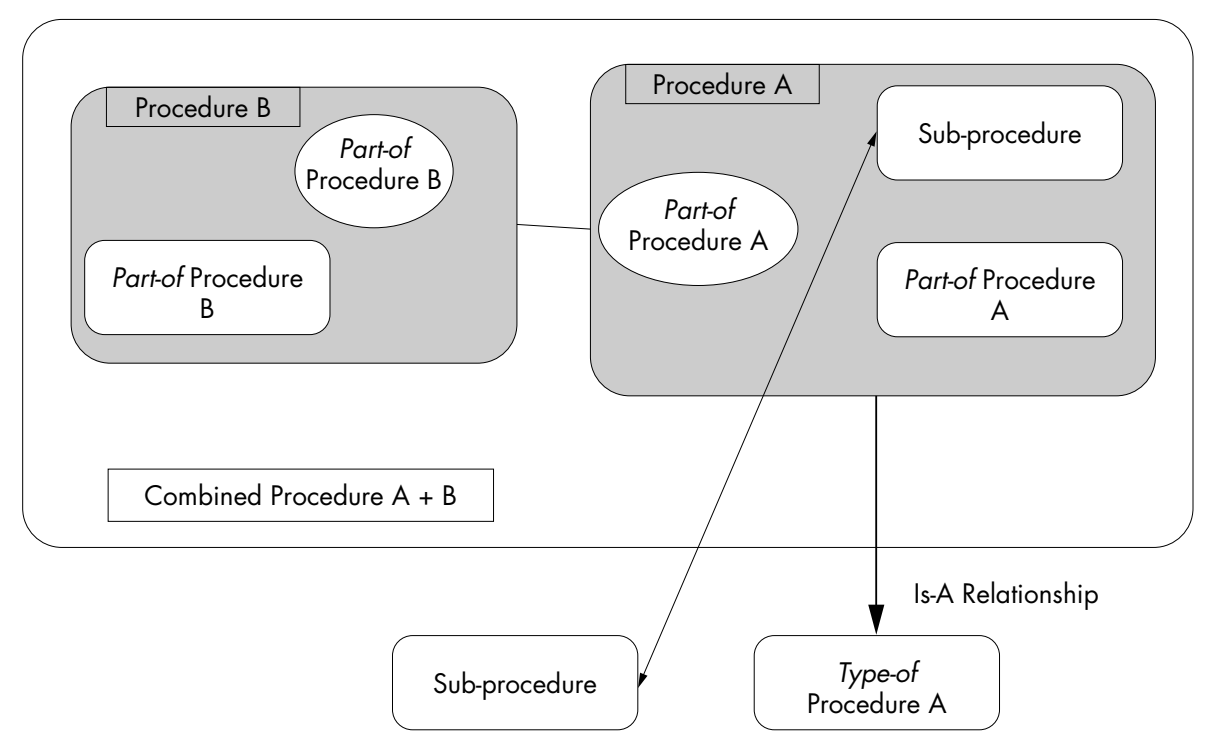

Figure 3 Procedure concept relationships.

for his consent beforehand. Equally, a variation that does not affect any of those elements does not need to be communicated to the patient.

\section{ii) Sectionalisation}

In Davis, McCullough J introduced the concept of sectionalisation. While his judgment does not fully explicate the meaning of sectionalisation certain inferences are possible. An intuitive approach to the use of such a term would suggest that McCullough $\mathrm{J}$ meant that a separate consent is not required for each step of the procedure. To ask the patient whether he agrees to an incision, and subsequent closure, of each abdominal layer when gaining consent for an appendicectomy would be to push the information demands of consent to a ridiculous extreme. In this sense, the concept of sectionalisation is a legitimate tool for delimiting the type of information that should be communicated to the patient. McCullough's concept, however, appears to go further than this. Thus, he states: "once this degree of sectionalisation is accepted, how long will it be before the court is invited to say that separate consent should be sought for separate steps in the surgical procedure". ${ }^{6}$ Although his concept goes beyond the steps of a procedure it does not extend to obviously different operations. As he explains: "Clearly, if it is proposed that a patient should undergo two separate operations it is the duty of the doctors to give the patient appropriately full information about each of them. This is so whether they are to be performed on two occasions or one" ${ }^{\prime 6}$

It is submitted that McCullough's use of the concept of sectionalisation epitomises the judiciary's distaste for an action bought in trespass. It is also suggested, however, that he has oversimplified the concept of a medical procedure by operating at too high a level of the procedure hierarchy. The component parts of a procedure lie in the middle ground between the steps of a procedure and the possibility of two separate procedures. With a small leap of faith it is arguable that the parts of a procedure are what McCullough had in mind when arguing against a sectionalised consent. It is suggested, however, that the parts are not the sole components of a medical procedure and it is too simple to use a concept of a medical procedure divisible only into parts or separate procedures.

\section{iii) The components of a medical procedure}

The argument in Davis and Sinclair was that if $<x>$ is a part of $<y>$ then consent for $\langle x>$ will be subsumed by consent for $<y>$. In Rizzo and the GMC case, this argument was implicitly rejected, and where a component of a procedure was varied in a way that had actual or potential consequences for the patient, the prior consent would be inadequate. The judgments in Davis and Sinclair are open to criticism because they drew false conclusions about the nature of the procedure based on a deficient conception of a medical procedure. The implication of Davis is, an anaesthetic is an anaesthetic is an anaesthetic. Similarly, Sinclair implies that, providing the baby is born through the vagina, a vaginal delivery is always a vaginal delivery regardless of what else is done. These conceptions of a medical procedure ignore both the hierarchical and the intraconceptual complexities.

The conceptual relationships that need to be distinguished are (see figure 3 ):

- a procedure;

- a sub-procedure (major and minor);

- a combined procedure;

- an example-of a procedure;

- the parts-of a procedure; and

- the types-of a procedure.

A sub-procedure may exist both as a part-of a larger procedure or as a procedure in its own right. If the sub-procedure is separated from the procedure then we are left with the main body of the procedure. Each individual occurrence of a particular concept is an example-of that concept. Just as the whole procedure, when performed, is an example-of the concept so the main body of the procedure remains an example-of the concept (when categorised at the basic level of the hierarchy), albeit a deficient one. How deficient an example-of the concept depends on the role played by the sub-procedure. If removal or variation of a component means that the concept has become a different concept the component is best viewed as an essential part-of the procedure rather than as a sub-procedure.

As an example, a general anaesthetic is essentially the administration of an anaesthetic drug to render the patient reversibly unconscious and allow an unpleasant or painful procedure to be performed. An intravenous analgesic may be administered as a sub-procedure within a general anaesthetic. Administration of an intravenous analgesic is a procedure in its own right. When given as an adjunct to a general anaesthetic it augments the procedure, but does not alter it sufficiently to require a new concept. If the analgesic is not given, the procedure remains a general anaesthetic although perhaps a less than adequate example of one. A sub-procedure, 
Table 1 Characteristics of procedure typology

\begin{tabular}{llll}
\hline Characteristic & Parts-of & Sub-procedure & Combined procedure \\
\hline Entailment & Entailed by procedure & Not entailed by main procedure & Not entailed by primary procedure \\
Effect of inclusion & $\begin{array}{l}\text { Does not change the nature } \\
\text { of the procedure }\end{array}$ & $\begin{array}{l}\text { May (Major sub-procedure) or may not change } \\
\text { (Minor sub-procedure) the nature of the procedure }\end{array}$ & $\begin{array}{l}\text { Will always change the nature of the } \\
\text { primary procedure } \\
\text { Purpose }\end{array}$ \\
$\begin{array}{l}\text { Enables/furthers the purpose } \\
\text { of the procedure }\end{array}$ & $\begin{array}{l}\text { Adjunctive to the purpose of the procedure } \\
\text { Is not a stand alone procedure }\end{array}$ & May exist as a stand alone procedure & May exist as a stand alone procedure \\
\hline
\end{tabular}

then, is a lesser procedure performed in conjunction with a greater procedure.

Sub-procedures may be sub-divided into major and minor subprocedures. The distinction is necessary because sub-procedures vary in the effect they have on the nature of the procedure. Minor sub-procedures do not require the creation of a sub-category concept while major sub-procedures do affect the nature of the procedure sufficiently for a new concept to be created. This new concept exists in a parent-child relationship with the original procedure. By including a major sub-procedure, the relationship has been altered from an example-of to a typeof the parent procedure concept. I will discuss the difference between major and minor sub-procedures in relation to the cases, which should help explain the distinction (see below).

A combined procedure is one in which two or more separate procedures are performed together, generating a new procedure. If the component procedures are separated we are left with two or more complete procedures and the combined procedure is made non-existent. For example, the operation of hysterectomy and bilateral salpingo-oophorectomy is a combined procedure. Both the hysterectomy and oophorectomy are procedures in their own rights that may be performed independently, but in neither case could performance of the individual procedure be considered performance of the combined procedure.

The parts-of a procedure are the components of a procedure that are not normally stand alone procedures, although they may be separated spatially, temporally or through being performed by different actors. For example, the skin incision, and the incision through the various layers of the abdominal wall are parts-of an abdominal procedure such as an appendicectomy. The characteristics of these concepts are summarised in table 1.

The types-of a procedure refers to subordinate level concepts in a classification hierarchy. Thus, if the procedure is cholecystectomy, the types-of cholecystectomy might include; "standard incision" cholecystectomy, "mini-laparotomy" cholecystectomy, and laparoscopic cholecystectomy.

\section{THE CASES REVISITED}

\section{i) Davis v Barking, Havering and Brentwood HA}

The provision of analgesia here is adjunctive to the anaesthetic rather than serving an entirely separate purpose. Thus, it should not be considered a combined procedure. When used as an adjunct, it is arguable that the caudal block would be the most appropriate choice for providing supplemental analgesia. Since, however, there are many different analgesic options, a caudal block is not entailed by the concept of a general anaesthetic. It would even be possible to perform the surgery without any supplemental analgesia. Further, the provision of analgesia may be a procedure in its own right. As such, the analgesic component of the anaesthetic is a sub-procedure rather than a part-of the procedure.

When considering whether the provision of analgesia is a minor or major sub-procedure it is important to realise that the answer will vary depending on the type of analgesia. Intravenous analgesia, which uses the same route of administration as the induction agent, and has broadly the same effects and risk profile as the general anaesthetic, should be considered a minor sub-procedure. The caudal block, on the other hand, introduces a new invasion of bodily integrity and has a markedly different risk and effects profile from a general anaesthetic. $^{20}$ Thus, the caudal anaesthetic is a major sub-procedure and should not be incorporated as a component of an anaesthetic without a separate consent.

\section{ii) The GMC case}

As with the caudal anaesthetic in Davis, the insertion of a rectal suppository introduces a new route of administration. The GMC was justified in relying on the fact that the woman would not have expected the lower part of her body to be interfered with. The provision of anaesthesia does not entail the use of a suppository and because of its route of administration the use of a suppository should be seen as a major sub-procedure. This is especially so since the anogenital area is one of particular sensitivity. Thus, the consent for a general anaesthetic does not subsume the consent for the rectal suppository and specific permission should be sought before its use.

\section{iii) The US cases}

The question of how a forceps delivery procedure relates to a vaginal delivery is perhaps more subtle. Intuitively, the use of forceps would be a type-of vaginal delivery rather than an example-of a vaginal delivery. This would suggest that the use of forceps to assist a manual delivery would be a major sub-procedure. The model would also support this view. Although the use of forceps does not introduce a new breach of bodily integrity, it does affect the risk profile associated with a manual vaginal delivery, as well as being a more traumatic experience for the mother. Both of these factors suggest that where forceps may be required the physician should seek the woman's consent. Nix CJ, in Sinclair, has confused the type-of relationship with the example-of relationship. Thus, the decision in Rizzo is to be preferred to the decision in Sinclair.

\section{CONCLUSION}

It is apparent from the cases that it is not always intuitive or a matter of common sense to decide when a variation in a procedure alters the procedure sufficiently for the patient's consent to be invalidated. Some variations, when they involve parts-of the procedure or minor sub-procedures may be subsumed by the procedure and the prior consent will remain valid. Where the variation involves a major sub-procedure (or the addition of a new procedure) then the prior consent will be inadequate. I have developed a model that should assist in determining when a variation is significant enough to require specific consent. ${ }^{21}$

If the function of "all propositions which have a factual content ... is to provide a rule for the anticipation of experience", ${ }^{22}$ then it is important that the propositions are accurate and sufficient to allow "the exclusion of relevant alternatives" ${ }^{23}$ Thus, the information provided as part of the consent process should place the patient in a position where knowledge of the risks and effects of that procedure is entailed 
by the patient's grasp of the procedure. It is hoped that the model will facilitate this and clarify the physician's duty to disclose.

Some support for the model already exists in the literature. In one study $98 \%$ of patients believed that rectal administration of analgesia should always be discussed in advance. Specific comments included adjectives such as "degrading" and "horrible". ${ }^{24}$ Similarly, in another study, $74 \%$ of patients preferred the intravenous to the rectal route which they said was "undignified", an "invasion", "embarrassing", and "humiliating"; $7.6 \%$ even considered it an "assault". ${ }^{25}$ Since these studies were performed for other reasons, however, the support they provide is limited. Thus, further studies are necessary to specifically address some of the relevant issues.

\section{ACKNOWLEDGEMENT}

I would like to thank Professor Sheila McLean for helpful criticism of an initial draft, and Professor Jonathan Montgomery, whose services as a sounding board were invaluable. I would also like to thank the anonymous assessors for their helpful criticism.

\section{REFERENCES AND NOTES}

1 Hurd HM. The moral magic of consent. Legal Theory 1996;2:121-46;

Alexander L. The moral magic of consent (II). Legal Theory 1996;2: 165-74.

2 Schloendorff v Society of New York Hospital 211 NY 125 at 129 105 NE 92, 93 (1914) per Cardozo J. From a moral perspective see-for example, Gillon R. Philosophical medical ethics. Chichester: John Wiley \& Sons, 1985, 1992: 114; McLean S, Maher G. Medicine, morals and the law. Aldershot: Gower Publishing, 1983:79.

3 Chatterton v Gerson [1981] 1 All ER 257. This standard relates to trespass. An additional information requirement, notably in relation to risks, is required in negligence. However, the distinction, although important, is not relevant for the purposes of this paper. In this article, I am addressing the overall adequacy of the disclosed information rather than whether that information is regulated in trespass or negligence. Of the cases, only Davis was brought as a trespass action, and in that case, McCullough J held (obiter-incidental to the reason for the judge's decision) that the result would have been the same even had it been brought in negligence.

4 Davis v Barking, Havering and Brentwood Health Authority [1993] 4 Medical Law Reports 85.
5 A caudal anaesthetic is a type of epidural anaesthetic, which involves the insertion of a needle into the patient's lower back (at the level of the cleft of the buttocks) and the injection of local anaesthetic into the "space" just outside the tissues surrounding the spinal cord. It is most effective in the ano-genital region.

6 See reference 4: 90 .

7 Mitchell J. ABC of breast diseases: a fundamental problem of consent. British Medical Journal 1995;310:43-6.

8 Rizzo v Schiller 445 SE2d 153 (1994).

9 See reference 8: 155

10 Sinclair by Sinclair v Block 633 A.2d 1137 (1993).

11 See reference 10: 1138 .

12 See reference 10: 1140 .

13 Komatsu LK. Recent views of conceptual structure. Psychological Bulletin 1992;112:500-26; Medin DL. Concepts and conceptual structure. American Psychologist 1989:44:1469-81.

14 See: Ahn W. Why are different features central for natural kinds and artifacts?: the role of causal status in determining feature centrality Cognition 1998;69:135-76; Medin DL. Concepts and conceptua structure. American Psychologist, 1989;44:1469-81.

15 Brown R. How shall a thing be called? Psychological Review 1958;65: 14-21

16 Murphy GL, Lassaline ME. Hierarchical structure in concepts and the basic level of categorization. In: Lamberts K, Shanks D, eds. Knowledge, concepts and categories. Hove: Psychology Press, 1997: 93.

17 Assuming possession of the relevant concept.

18 Rosch E, Mervis CB, Gray WD, et al. Basic objects in natural categories. Cognitive Psychology 1976;8:382-439. The term "basic level" may appear counterintuitive since it refers to the level of usage rather than the level of classification. I am grateful to the anonymous reviewer for indicating this difficulty inherent in the Rosch et al's terminology.

19 Grice HP. Logic and conversation. In: Martnich AP, ed. The philosophy of language [3rd ed]. New York: Oxford University Press, 1996: $156-67$ at 159

20 See, for example: Kane RE. Neurological deficits following epidural or spinal anesthesia. Anesthesia \& Analgesia 1981;60:150-61. Since a caudal block is a type of epidural the nature of the risks is similar. However, the probability of their eventuating is lower.

21 It is recognised that the proposed model may have implications for those patients who do not want to know. This issue will need to be addressed and will form the subject of a future article.

22 Ayer AJ. Language, truth and logic. London: Penguin, 1990: 23.

23 Dretske FI. Knowledge and the flow of information. Oxford: Basi Blackwood, 1981: 129.

24 Vyryan HAL, Hanafiah Z. Patients' attitudes to rectal drug administration. Anaesthesia 1995;50:983-4.

25 Colbert SA, O'Hanlon D, McAnena O, et al. The attitudes of patients and health care personnel to rectal drug administration following day case surgery. European Journal of Anaesthesiology 1998;15:422-6. 